\author{
Paweł Stróżecki ${ }^{1}$, Juliusz Polak², Magdalena Jabłońska², Zbigniew Włodarczyk ${ }^{3}$ \\ ${ }^{1}$ Department of Nephrology, Hypertension and Internal Medicine, Collegium Medicum, Bydgoszcz, Nicolaus Copernicus University, Torun, \\ Poland \\ ${ }^{2}$ Students Scientific Society, Collegium Medicum, Bydgoszcz, Nicolaus Copernicus University, Torun, Poland \\ ${ }^{3}$ Department of Transplantology and Surgery, Collegium Medicum, Bydgoszcz, Nicolaus Copernicus University, Torun, Poland
}

\title{
Orthostatic hypotension in kidney transplant recipients
}

\section{Corresponding author:}

Paweł Stróżecki, Department of Nephrology, Hypertension and Internal Medicine, University Hospital No 1, Skłodowskiej-Curie 9 85-094 Bydgoszcz, Poland e-mail: st_pawel@cm.umk.pl
Medical Research Journal 2021; Volume 6, Number 4, 288-294 10.5603/MRJ.a2021.0055 Copyright (C) 2021 Via Medica ISSN 2451-2591 e-ISSN 2451-4101

\begin{abstract}
Introduction: Orthostatic hypotension $(\mathrm{OH})$ is associated with increased morbidity and mortality. The prevalence of $\mathrm{OH}$ in the general population is $2-26 \%$ and is strongly associated with age. The prevalence of $\mathrm{OH}$ in kidney transplant recipients (KTRs) is unknown. The study aimed to investigate the prevalence of $\mathrm{OH}$ among KTRs and to identify factors associated with this phenomenon. Material and methods: The study was designed as a cross-sectional analysis in KTRs at a routine visit in an outpatient department. Fifty KTRs aged $60 \pm 12$ years ( 21 female and 29 male) were investigated. The kidney transplant follow-up was $72 \pm 63$ months (range 3-243). All subjects underwent an orthostatic test (OT). Clinical and laboratory data were also analyzed.

Results: $\mathrm{OH}$ was diagnosed in 17 (34\%) patients (the $\mathrm{OH}+$ group). KTRs with $\mathrm{OH}$ were older (63 $\pm 9 \mathrm{vs.}$ $54 \pm 13 ; p=0.01$ ) and were more often diabetic ( $53 \%$ vs. $24 \% ; p=0.04$ ) than patients without $\mathrm{OH}$. $\mathrm{OH}+$ patients had higher supine systolic blood pressure (152 \pm 23 vs. $134 \pm 16 ; p=0.006)$ and higher supine pulse rate $(75 \pm 12$ vs. $68 \pm 10 ; p=0.047)$. A higher percentage of $\mathrm{OH}+$ patients were taking beta-blockers (94\% vs. $70 \% ; p=0.048$ ) and calcium antagonists ( $88 \%$ vs. $52 \% ; p=0.01)$. Pulse rate did not change significantly during the $\mathrm{OT}$ in patients with $\mathrm{OH}$, while it increased significantly in patients without $\mathrm{OH}$.

Conclusions: Orthostatic hypotension is a common finding among kidney transplant patients, particularly elderly patients with coexisting diabetes. Awareness of such a high prevalence of $\mathrm{OH}$ should encourage physicians to perform the orthostatic test in KTRs. Concomitant pulse rate measurement and analysis of current medications may contribute to a better understanding of $\mathrm{OH}$ pathogenesis in an individual patient. Key words: blood pressure, kidney transplant, orthostatic hypotension, pulse rate
\end{abstract}

Med Res J 2021; 6 (4): 288-294

\section{Introduction}

Orthostatic hypotension $(\mathrm{OH})$, a drop in blood pressure after taking a vertical position, is associated with an increased risk of mortality and cardiovascular (CV) events [1-4]. Orthostatic hypotension is defined as a reduction in systolic blood pressure (SBP) of $\geq 20 \mathrm{mmHg}$ or diastolic blood pressure (DBP) of $\geq 10 \mathrm{mmHg}$ within 3 minutes of standing [5]. The prevalence of $\mathrm{OH}$ in the general population is $5-26 \%$ and is strongly associated with age $[3,4,6]$. In population-based cohorts, the prevalence of $\mathrm{OH}$ ranged from $2 \%$ among persons aged $45-49$ years, $9.4 \%$ among persons $60-64$ years [4], 14.8\% among persons aged 65-69 years, up to $26 \%$ in a group of people aged 85 and older [6]. Among elderly patients in nursing homes and geriatric wards, the prevalence of $\mathrm{OH}$ is $50 \%[7,8]$. It should be, however, noted, that $\mathrm{OH}$ is asymptomatic in the vast majority (about $90 \%$ ) of patients [6]. $\mathrm{OH}$ frequently affects patients with neurodegenerative disease, diabetes, hypertension, chronic kidney disease, and chronic heart failure $[3,8,9]$. Autonomic neuropathy seems to be the main cause of $\mathrm{OH}$. Several drugs were also identified to be associated with $\mathrm{OH}$. Orthostatic hypotension is considered a risk predictor of falls, disability, and impaired quality of life, however, clinical data are inconsistent $[7,8,10]$. There is a lack of clinical data regarding the epidemiology of $\mathrm{OH}$ among KTRs. 


\section{Aim of the study}

The study aimed to investigate the prevalence of $\mathrm{OH}$ among KTRs and to identify factors associated with this phenomenon.

\section{Material and methods}

The study was designed as a cross-sectional analysis. Kidney transplant recipients from the Transplantology Outpatient Department of the Jurasz University Hospital in Bydgoszcz, Poland, were recruited to the study. The study was performed in accordance with the ethical standards of the Declaration of Helsinki (Approval of the local Bioethics Committee KB 798/2019). Informed consent was obtained from each participant. Fifty-six KTRs were asked to participate in the study, 6 patients refused. Fifty KTRs aged 31-75 years (mean \pm SD: $60 \pm 12$ ) were included in the study. There were 29 male and 21 female patients in the study group. The underlying renal disease was (1) glomerulonephritis in 16 (32\%), (2) polycystic kidney disease (ADPKD) in 11 (22\%), (3) diabetic nephropathy in $7(14 \%)$, (4) hypertensive nephropathy in $6(12 \%)$, (5) interstitial nephritis (including kidney stone disease and gout nephropathy) in 5 (10\%), (6) other or unknown in $5(10 \%)$. Detailed anamnesis including the history of diabetes, hypertension, coronary heart disease, stroke, atrial fibrillation, episodes of falls, or fainting was performed. Fasting blood was collected for laboratory analyses. Patients' charts were analyzed for current medical therapy. An orthostatic test (OT) according to the guidelines of the European Cardiac Society/European Hypertension Society (2018) was performed for each participant [11]. SBP, DBP, and pulse rate $(\mathrm{PR})$ recordings were taken using oscillometric blood pressure monitor Microlife BP B3 AFIB (Microlife AG, Widnau, Switzerland). Figure 1 presents the diagram of the OT performed in a study. All OTs were done between 8.00 and 10.00 A.M.

\section{Laboratory measurements}

Laboratory measurements were performed on $\mathrm{Ab}$ bott Architect ci8200 analyzer using Abbott Laboratories commercial reagents (Abbott Laboratories, Abbott Park, IL, USA). Glomerular filtration rate was estimated (eGFR) using CKD-EPI equation [12].

\section{Statistical analysis}

Statistical analysis was performed using the Statistica 13.1 software. The distribution of variables was analyzed using the Shapiro-Wilk test. Normally

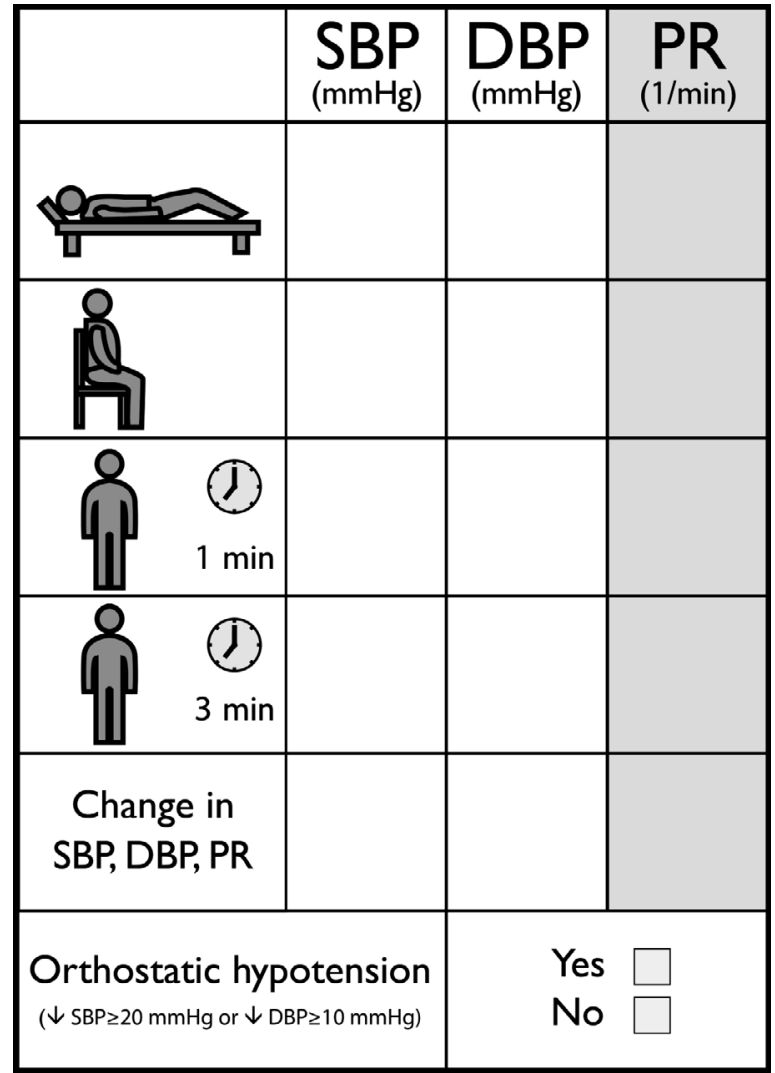

Figure 1. The diagram of orthostatic test with systolic blood pressure (SBP), diastolic blood pressure (DBP), and pulse rate $(\mathrm{PR})$ measurements

distributed data are presented as mean \pm standard deviation (SD). Not normally distributed data are shown as median and range. Categorical variables are presented as percentages. The comparison between groups was performed using Student's t-test. For not-normally distributed data the Mann-Whitney U-test was used. Qualitative data were compared using $\chi^{2}$ - test. One-way analysis of variance (ANOVA) was used to compare the means in variables with multiple measurements. P-value $<0.05$ was considered statistically significant.

\section{Results}

$\mathrm{OH}$ was diagnosed in 17 (34\%) patients (the $\mathrm{OH}+$ group). The clinical and laboratory characteristics of the $\mathrm{OH}+$ group and patients without $\mathrm{OH}$ (the $\mathrm{OH}$ - group) are presented in Table 1.

KTRs with $\mathrm{OH}$ were older $(63 \pm 9$ vs. $54 \pm 13$; $\mathrm{p}=0.01)$ and were more often diabetic (53\% vs. $24 \%$; $\mathrm{p}=0.04)$. Higher percentage of $\mathrm{OH}+$ patients were taking beta-blockers ( $94 \%$ vs. $70 \% ; p=0.048)$, calcium antagonist $(88 \%$ vs. $52 \% ; p=0.01)$, and statin $(77 \%$ 
Table 1. Characteristics of kidney transplant recipients with orthostatic hypotension $(\mathrm{OH}+)$ and without orthostatic hypotension $(\mathrm{OH}-)$

\begin{tabular}{|c|c|c|c|}
\hline & $\begin{array}{c}\mathrm{OH}+ \\
(\mathrm{n}=17)\end{array}$ & $\begin{array}{c}\text { OH- } \\
(n=33)\end{array}$ & P-value \\
\hline Age (years) & $63 \pm 9$ & $54 \pm 13$ & 0.01 \\
\hline Male gender n (\%) & $9(53 \%)$ & $20(61 \%)$ & 0.60 \\
\hline Kidney transplant follow-up (months) & $56 \pm 46$ & $81 \pm 69$ & 0.14 \\
\hline Hypertension n (\%) & $14(82 \%)$ & $28(85 \%)$ & 0.82 \\
\hline Diabetes n (\%) & $9(53 \%)$ & $8(24 \%)$ & 0.04 \\
\hline Coronary heart disease $\mathrm{n}(\%)$ & $2(11 \%)$ & $6(18 \%)$ & 0.56 \\
\hline Atrial fibrillation $\mathrm{n}(\%)$ & $2(12 \%)$ & $4(12 \%)$ & 0.97 \\
\hline History of falls n (\%) & $5(29 \%)$ & $7(21 \%)$ & 0.52 \\
\hline History of fainting $n(\%)$ & $7(41 \%)$ & $8(24 \%)$ & 0.22 \\
\hline History of stroke n (\%) & $2(12 \%)$ & $1(3 \%)$ & 0.21 \\
\hline Height (cm) & $169 \pm 7$ & $172 \pm 10$ & 0.34 \\
\hline Body mass (kg) & $80 \pm 8$ & $79 \pm 13$ & 0.62 \\
\hline Body mass index $\left(\mathrm{kg} / \mathrm{m}^{2}\right)$ & $28.0 \pm 2.8$ & $26.8 \pm 5.0$ & 0.29 \\
\hline Serum creatinine $(\mathrm{mg} / \mathrm{dL})$ & $1.23 \pm 0.52$ & $1.43 \pm 0.66$ & 0.26 \\
\hline eGFR $\left(\mathrm{mL} / \mathrm{min} / 1.73 \mathrm{~m}^{2}\right)$ & $63 \pm 22$ & $58 \pm 22$ & 0.45 \\
\hline Hemoglobin (g/dL) & $13.4 \pm 2.0$ & $13.5 \pm 1.6$ & 0.93 \\
\hline Total cholesterol (mg/dL) & $188 \pm 46$ & $194 \pm 39$ & 0.74 \\
\hline LDL-cholesterol (mg/dL) & $113 \pm 41$ & $125 \pm 32$ & 0.45 \\
\hline HDL-cholesterol (mg/dL) & $56 \pm 16$ & $56 \pm 15$ & 0.99 \\
\hline Triglycerides (mg/dL) & $146 \pm 49$ & $156 \pm 73$ & 0.71 \\
\hline Sodium (mmol/L) & $141 \pm 4$ & $143 \pm 3$ & 0.17 \\
\hline Potassium (mmol/L) & $4.4 \pm 0.5$ & $4.3 \pm 0.4$ & 0.44 \\
\hline Uric acid (mg/dL) & $7.1 \pm 2.2$ & $7.6 \pm 1.8$ & 0.59 \\
\hline BUN (mg/dL) & $29 \pm 12$ & $30 \pm 16$ & 0.80 \\
\hline SBP supine $(\mathrm{mmHg})$ & $152 \pm 23$ & $134 \pm 16$ & 0.006 \\
\hline DBP supine $(\mathrm{mmHg})$ & $86 \pm 10$ & $83 \pm 11$ & 0.22 \\
\hline SBP sitting (mmHg) & $135 \pm 21$ & $137 \pm 17$ & 0.53 \\
\hline DBP sitting (mmHg) & $81 \pm 11$ & $85 \pm 12$ & 0.28 \\
\hline SBP standing after 1 minute $(\mathrm{mmHg})$ & $128 \pm 22$ & $130 \pm 17$ & 0.79 \\
\hline DBP standing after 1 minute $(\mathrm{mmHg})$ & $77 \pm 11$ & $84 \pm 11$ & 0.06 \\
\hline SBP standing after 3 minutes $(\mathrm{mmHg})$ & $129 \pm 24$ & $132 \pm 18$ & 0.63 \\
\hline DBP standing after 3 minutes $(\mathrm{mmHg})$ & $79 \pm 12$ & $86 \pm 11$ & 0.06 \\
\hline Pulse rate supine & $75 \pm 12$ & $68 \pm 10$ & 0.047 \\
\hline Pulse rate sitting & $78 \pm 12$ & $72 \pm 11$ & 0.09 \\
\hline Pulse rate standing after 1 minute & $81 \pm 13$ & $78 \pm 11$ & 0.40 \\
\hline Pulse rate standing after 3 minutes & $81 \pm 12$ & $77 \pm 12$ & 0.25 \\
\hline Number of antihypertensive drugs & $3,1 \pm 0.9$ & $2.6 \pm 1.5$ & 0.16 \\
\hline Beta-blocker n (\%) & $16(94 \%)$ & $23(70 \%)$ & 0.048 \\
\hline Calcium antagonist $\mathrm{n}(\%)$ & $15(88 \%)$ & $17(52 \%)$ & 0.01 \\
\hline ACEI n (\%) & $4(24 \%)$ & $14(42 \%)$ & 0.19 \\
\hline Sartan n (\%) & $1(6 \%)$ & $3(9 \%)$ & 0.69 \\
\hline
\end{tabular}


Table 1 cont. Characteristics of kidney transplant recipients with orthostatic hypotension $(\mathrm{OH}+)$ and without orthostatic hypotension (OH-)

\begin{tabular}{lccc}
\hline & $\begin{array}{c}\mathbf{O H}+ \\
(\mathbf{n = 1 7})\end{array}$ & $\begin{array}{c}\text { OH- } \\
(\mathbf{n}=\mathbf{3 3})\end{array}$ & P-value \\
\hline Diuretic n (\%) & $8(47 \%)$ & $11(33 \%)$ & 0.34 \\
Alfa-blocker n (\%) & $7(41 \%)$ & $13(39 \%)$ & 0.90 \\
Other antihypertensives n (\%) & $1(6 \%)$ & $4(12 \%)$ & 0.49 \\
Tacrolimus n (\%) & $14(82 \%)$ & $23(70 \%)$ & 0.33 \\
Cyclosporine n (\%) & $2(12 \%)$ & $7(21 \%)$ & 0.41 \\
Mycophenolate mofetil n (\%) & $16(94 \%)$ & $29(88 \%)$ & 0.49 \\
Everolimus n (\%) & $2(12 \%)$ & $1(3 \%)$ & 0.22 \\
Azathioprine n (\%) & $0(0 \%)$ & $2(6 \%)$ & 0.30 \\
Steroid n (\%) & $17(100 \%)$ & $32(97 \%)$ & 0.47 \\
Statin n (\%) & $13(77 \%)$ & $13(39 \%)$ & 0.01 \\
\hline
\end{tabular}

ACEI — angiotensin converting enzyme inhibitors; BUN — blood urea nitrogen; DBP — diastolic blood pressure; eGFR — estimated glomerular filtration rate; HDL — high-density lipoprotein; LDL — low-density lipoprotein; SBP — systolic blood pressure

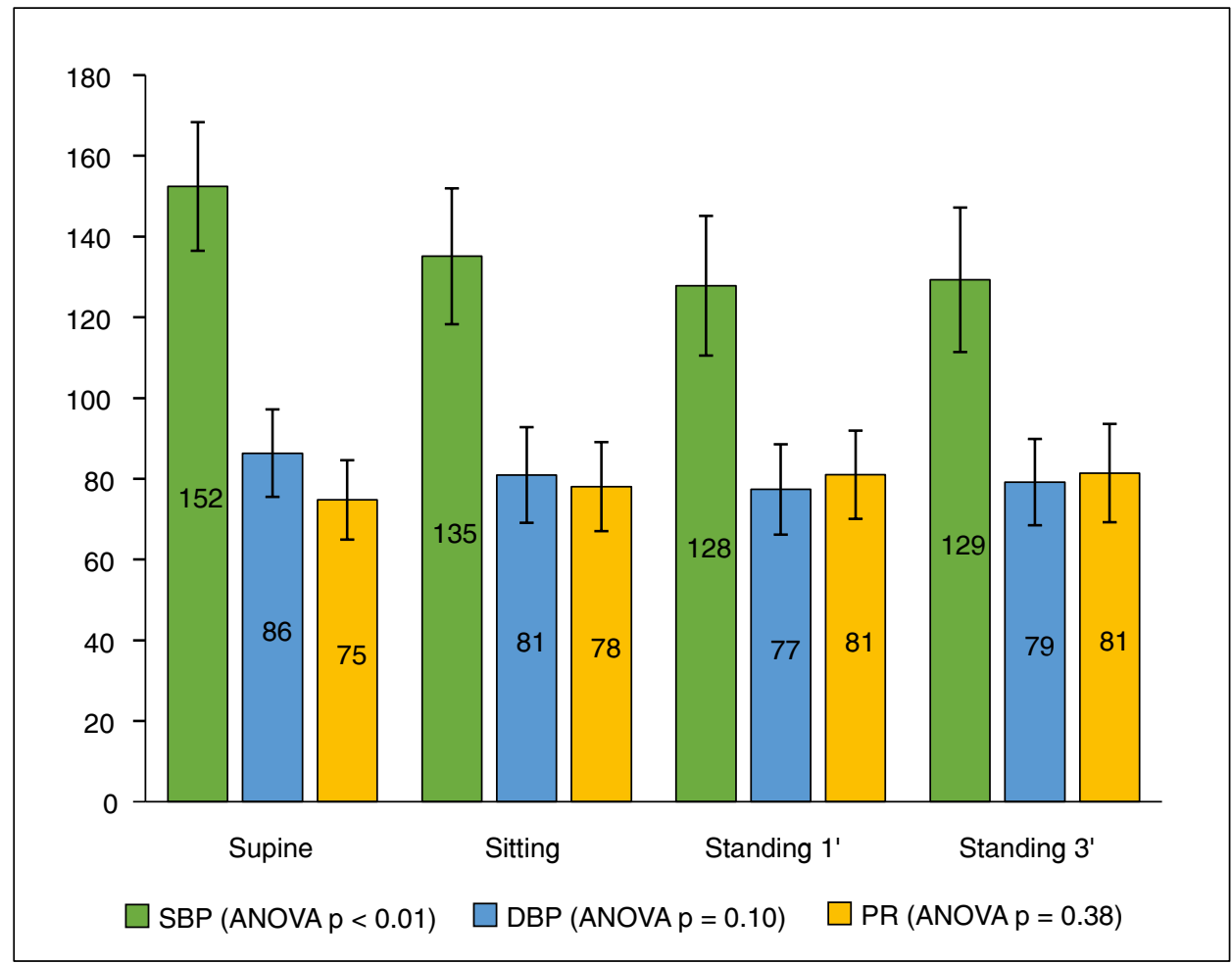

Figure 2. Changes in SBP, DBP, and PR in kidney transplant recipients with orthostatic hypotension (the $\mathrm{OH}+\mathrm{Group}$ ); DBP — diastolic blood pressure; PR — pulse rate; SBP — systolic blood pressure

vs. 39\%; $p=0.01$ ). There were no significant differences in the history of falls (29\% vs. $21 \%$; $p=0.52)$ and the history of fainting $41 \%$ vs. $24 \%$; $p=0.22$ ) between the $\mathrm{OH}+$ and $\mathrm{OH}$ - groups. $\mathrm{OH}+$ patients had higher supine systolic blood pressure (152 \pm 23 vs. $134 \pm 16$; $p=0.006)$ and higher supine pulse rate $(75 \pm 12$ vs. $68 \pm 10$; $p=0.047)$. Pulse rate did not change significantly during the OT in patients with $\mathrm{OH}$, while it increased significantly in patients without $\mathrm{OH}$ (ANOVA $\mathrm{p}<0.001)$. Patterns of SBP, DBP and PR changes during the OT in $\mathrm{OH}+$ and $\mathrm{OH}$ - patients are shown in Figure 2 and 3 , respectively. 


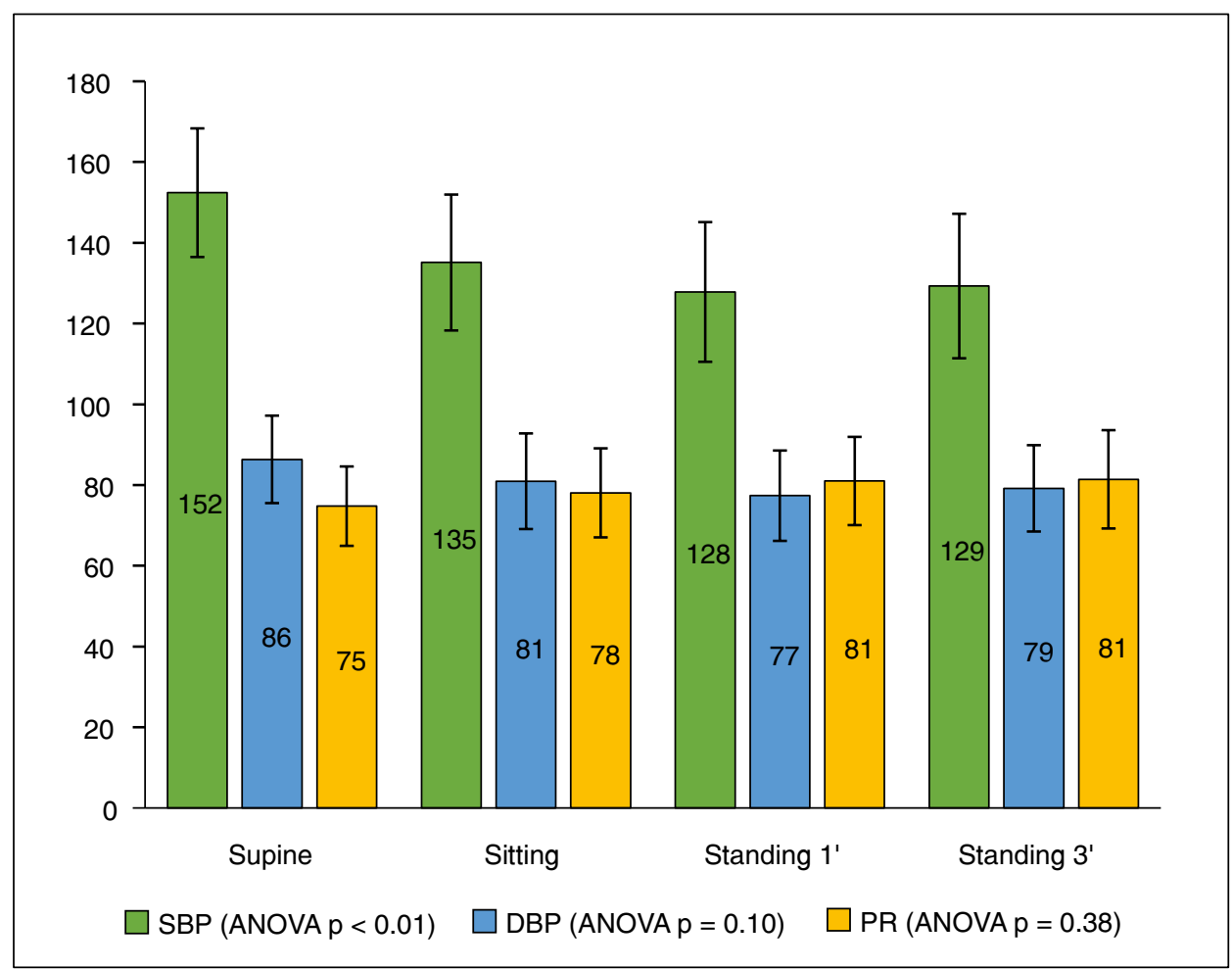

Figure 3. Changes in SBP, DBP, and PR in kidney transplant recipients without orthostatic hypotension (the OH- Group); DBP — diastolic blood pressure; PR — pulse rate; SBP — systolic blood pressure

\section{Discussion}

Out of 50 KTRs included in the study, 17 (34\%) met the criteria of $\mathrm{OH}$. To our best knowledge, it is the first study documenting such a high prevalence of $\mathrm{OH}$ among KTRs. It indicates that the prevalence of $\mathrm{OH}$ among KTRs is much higher than in the general population. In a population-based Atherosclerosis Risk in Communities (ARIC) study, the prevalence of $\mathrm{OH}$ among the middle-aged population was $4.9 \%$, with $9.4 \%$ prevalence among patients aged $60-64$ years [4]

The prevalence of $\mathrm{OH}$ increases with age $[4,6]$. In the general population, $\mathrm{OH}$ was more prevalent in patients with diabetes and with hypertension [4]. Chronic kidney disease (CKD) is associated with a high prevalence of $\mathrm{OH}$. In a group of asymptomatic CKD patients (mean age 69 years, eGFR $36 \mathrm{~mL} / \mathrm{min} / 1.73 \mathrm{~m}^{2}$ ), the prevalence of $\mathrm{OH}$ was $38 \%$ [13]. In the present study, KTRs with $\mathrm{OH}$ were older and more often diabetic than patients without $\mathrm{OH}$. There was no difference in the history of falls or fainting between the $\mathrm{OH}+$ and $\mathrm{OH}$ - groups. It is in line with earlier studies showing that $\mathrm{OH}$ was asymptomatic in the majority of patients $[6,13]$. If patients are screened for $\mathrm{OH}$ based only on clinical symptoms connected with blood pressure fall after standing, the detected prevalence would underestimate the real prevalence [6, 8]. Our study revealed that every third patient at routine visit presented $\mathrm{OH}$.
Thus, it seems reasonable to include an OT into daily clinical practice in KTRs.

In our study different SBP, DBP, and PR patterns were found in the $\mathrm{OH}+$ and $\mathrm{OH}$ - groups. In $\mathrm{OH}+$ patients, SBP significantly fell during the orthostatic test, while DBP and PR did not change (Fig. 2). In $\mathrm{KTR}$ s without $\mathrm{OH}$, there were no significant changes in SBP and DBP, while PR increased significantly (Fig. 3). Baseline (supine) PR was higher in $\mathrm{OH}+$ patients even though most of them (94\%) were being treated with beta-blockers.

Several studies investigating the association between antihypertensive medications and $\mathrm{OH}$ found a relationship between antihypertensive therapy per se and specific classes of antihypertensive drugs, like alpha-blockers, diuretics, and beta-blockers [4, 6 , 14-16]. Also, nitrates, anti-Parkinson drugs, and tricyclic antidepressants may be involved in $\mathrm{OH}$ pathogenesis [8]. In a historical study in KTRs, significant $\mathrm{OH}$ was observed after the introduction of alpha-blocker prazosin [14]. Newer data regarding the association between $\mathrm{OH}$ and antihypertensive drugs in KTRs is lacking. In our study, it was found that KTRs with $\mathrm{OH}$ were more often treated with beta-blockers and calcium channel antagonists. It is of interest that there were no significant differences in alpha-blocker ( $41 \%$ vs. $39 \%, p=0.90$ ) and diuretic $(47 \%$ vs. $33 \% ; p=0.34)$ usage between the $\mathrm{OH}+$ and $\mathrm{OH}$-groups. 
In several studies in non-transplant populations association between treatment with beta-blockers and $\mathrm{OH}$ was documented $[6,13,15]$. In AASK Trial the risk of $\mathrm{OH}$ was higher among patients treated with metoprolol than in patients receiving ramipril or amlodipine [15]. In the ARIC study, there was no difference in the proportion of $\mathrm{OH}+$ and $\mathrm{OH}$ - patients using beta-blockers, angiotensin-converting enzyme inhibitors, calcium channel blockers, or diuretics among hypertensive subjects. However, in normotensive patients with $\mathrm{OH}$, beta-blockers were more commonly used compared to those without $\mathrm{OH}$ [4]. It may suggest that beta-blockers may attenuate the physiological cardiac response to the change from a supine to an upright position.

Autonomic neuropathy, specifically sympathetic autonomous system neuropathy, seems to be the main cause of $\mathrm{OH}[7,9,17]$. A change from a lying to standing position normally results in activation of a baroreceptor-initiated, centrally-mediated sympathetic reflex, leading to an increase in peripheral vascular resistance and cardiac acceleration [18]. Gerhardt et al. showed in a group of KTRs that abnormal blood pressure response to active standing up was associated with diminished baroreceptor sensitivity [19].

Elevated resting heart rate (HR) is considered a marker of autonomic dysfunction [18]. Resting tachycardia and a fixed heart rate are characteristic late findings in diabetic patients with autonomic neuropathy [18]. The absence of a compensatory PR increase during OTs observed in the present study seems to confirm the role of autonomic neuropathy in $\mathrm{OH}$. On the other hand, exaggerated tachycardia during OTs (increase in heart rate $>15$ beats per minute) may suggest volume depletion or other secondary causes rather than a neurogenic form of $\mathrm{OH}[7,20]$.

The authors of the $2018 \mathrm{ESC} / \mathrm{ESH}$ Guidelines for the management of arterial hypertension suggest that heart rate should be recorded at the time of blood pressure measurement during the OT [11]. Automatic blood pressure devices allow measuring SBP, DBP, and PR simultaneously. Analysis of PR change during OT gives valuable information about cardiac response to change in body position from supine to standing. Arnold et al. also suggest that measurement of HR during OT allows assessing the integrity of baroreflex function [7]. It is also notable that resting $\mathrm{HR}$ is an independent predictor of cardiovascular morbidity and mortality [21].

Research resources on $\mathrm{OH}$ among kidney transplant recipients are severely limited. Interestingly, in a study investigating pancreas-kidney transplant (SPKT) recipients, $\mathrm{OH}$ developed postoperatively in $28 \%$ of patients aged 25-53 years [22]. In a comparative group of diabetic kidney-only transplant recipients, postoperative $\mathrm{OH}$ developed in only 1 out of 43 patients (2.3\%). In most SPKT patients, postoperative $\mathrm{OH}$ was a symptom- atic condition and required discontinuation of antihypertensive therapy; most patients also required midodrine for symptomatic relief. In this study, post-transplant $\mathrm{OH}$ in SPKT patients resolved within 3 weeks to 9 months in all but 1 patient [22]. The pathogenesis of this transient $\mathrm{OH}$ in SPKT is unclear. This type of $\mathrm{OH}$ seems to be related not only to pre-transplant neuropathy and post-transplant hypovolemia but also to hyperinsulinemia or vasoactive peptides imbalance associated with pancreas transplantation [22]. Transient postoperative $\mathrm{OH}$ in SPKT recipients appears to be a different phenomenon from $\mathrm{OH}$ during long-term follow-up in kidney transplant recipients.

It is unclear whether a diagnosis of $\mathrm{OH}$ should result in a reduction in antihypertensive treatment. There is a lack of such studies in KTRs. However recent analysis of SPRINT Study patients showed that the prevalence of $\mathrm{OH}$ was higher among patients assigned to standard treatment as compared with those assigned to intensive treatment [10]. In this study, $\mathrm{OH}$ was not associated with increased risk of CV events, syncope, or injurious falls but was associated with a higher risk of hypotension-related hospitalizations or emergency department visits [10]. The authors of this study concluded that the presence of symptomless $\mathrm{OH}$ should not be a reason for the down-titration of antihypertensive medications [10].

The present study has several limitations which arise from a small number of patients and the cross-sectional study design. In our study, the orthostatic test was performed only once in each patient. OT reproducibility (57-79\%) is not perfect [23]. As orthostatic response can vary during the day and over time, repeated OTs may result in a better understanding of this phenomenon [8]. Other authors suggest that the most sensitive and consistent measurements are obtained early in the morning when patients are more symptomatic due to nocturnal pressure natriuresis $[7,23]$. Thus, in the present study, all OTs were performed in the morning. Higher supine systolic blood pressure found in the $\mathrm{OH}+$ group may also suggest nocturnal hypertension in these patients. Automatic blood pressure monitoring would allow us to analyze this potential association.

All this data confirm the urgent need for further studies investigating the prevalence, pathogenesis, and therapeutic approach to $\mathrm{OH}$ among KTRs. Long-term observational studies would elucidate the prognostic significance of $\mathrm{OH}$ in kidney transplant recipients.

\section{Conclusions}

Orthostatic hypotension is a common finding among kidney transplant patients, particularly elderly patients with coexisting diabetes. Awareness of such a high prevalence of $\mathrm{OH}$ should encourage doctors to 
perform the orthostatic test in KTR. Concomitant pulse rate measurement and analysis of current medications may contribute to a better understanding of $\mathrm{OH}$ pathogenesis in individual patients.

\section{Conflict of interest: None}

Funding: None

Acknowledgments: The authors thank Tymoteusz Polak for the original artwork in Figure 1.

\section{References}

1. Fagard $\mathrm{RH}$, De Cort $\mathrm{P}$. Orthostatic hypotension is a more robust predictor of cardiovascular events than nighttime reverse dipping in elderly. Hypertension. 2010; 56(1): 56-61, doi: 10.1161/HYPERTENSIONAHA.110.151654, indexed in Pubmed: 20458003.

2. Fedorowski A, Hedblad Bo, Melander O. Early postural blood pressure response and cause-specific mortality among middle-aged adults. Eur J Epidemiol. 2011; 26(7): 537-546, doi: 10.1007/s10654-011-9578-1, indexed in Pubmed: 21487956.

3. Fedorowski A, Stavenow L, Hedblad Bo, et al. Orthostatic hypotension predicts all-cause mortality and coronary events in middle-aged individuals (The Malmo Preventive Project). Eur Heart J. 2010; 31(1): 85-91, doi: 10.1093/eurheartj/ehp329, indexed in Pubmed: 19696189.

4. Rose KM, Tyroler HA, Nardo CJ, et al. Orthostatic hypotension and the incidence of coronary heart disease: the Atherosclerosis Risk in Communities study. Am J Hypertens. 2000; 13(6 Pt 1): 571-578, doi: 10.1016/s0895-7061(99)00257-5, indexed in Pubmed: 10912737.

5. Consensus statement on the definition of orthostatic hypotension, pure autonomic failure, and multiple system atrophy. The Consensus Committee of the American Autonomic Society and the American Academy of Neurology. Neurology. 1996; 46(5): 1470, doi: 10.1212/wnl.46.5.1470, indexed in Pubmed: 8628505

6. Rutan GH, Hermanson B, Bild DE, et al. Orthostatic hypotension in older adults. The Cardiovascular Health Study. CHS Collaborative Research Group. Hypertension. 1992; 19(6 Pt 1): 508-519, doi: 10.1161/01.hyp.19.6.508, indexed in Pubmed: 1592445.

7. Arnold AC, Raj SR. Orthostatic Hypotension: a practical approach to investigation and management. Can J Cardiol. 2017; 33(12): 1725 1728, doi: 10.1016/j.cjca.2017.05.007, indexed in Pubmed: 28807522

8. Benvenuto LJ, Krakoff LR Morbidity and mortality of orthostatic hypotension: implications for management of cardiovascular disease. Am J Hypertens. 2011; 24(2): 135-144, doi: 10.1038/ajh.2010.146, indexed in Pubmed: 20814408.

9. Ricci F, De Caterina R, Fedorowski A. Orthostatic hypotension: epidemiology, prognosis, and treatment. J Am Coll Cardiol. 2015; 66(7)
848-860, doi: 10.1016/j.jacc.2015.06.1084, indexed in Pubmed: 26271068

10. Juraschek SP, Taylor AA, Wright JT, et al. SPRINT Research Group. Orthostatic hypotension, cardiovascular outcomes, and adverse events: results from SPRINT. Hypertension. 2020; 75(3): 660-667. doi: 10.1161/HYPERTENSIONAHA.119.14309, indexed in Pubmed: 31983312.

11. Williams B, Mancia G, et al. SpieringW, 2018 Practice guidelines for the management of arterial hypertension of the European Society of Hypertension and the European Society of Cardiology: ESH/ESC Task Force for the Management of Arterial Hypertension. J Hypertens. 2018; 36: 2284-2309

12. Levey AS, Stevens LA, Schmid CH, et al. CKD-EPI (Chronic Kidney Disease Epidemiology Collaboration). A new equation to estimate glomerular filtration rate. Ann Intern Med. 2009; 150(9): 604-612, doi: 10.7326/00034819-150-9-200905050-00006, indexed in Pubmed: 19414839

13. Januszko-Giergielewicz B, Gromadziński L, Dudziak M et al. Orthostatic hypotension in asymptomatic patients with chronic kidney disease. Medicina (Kaunas). 2019; 55(4), doi: 10.3390/medicina55040113, indexed in Pubmed: 31009994.

14. Curtis JR, Bateman FJ. Use of prazosin in management of hypertension in patients with chronic renal failure and in renal transplant recipients. $\mathrm{Br}$ Med J. 1975; 4(5994): 432-434, doi: 10.1136/bmj.4.5994.432, indexed in Pubmed: 811312

15. Juraschek SP, Appel LJ, Miller ER, et al. Hypertension treatment effects on orthostatic hypotension and its relationship with cardiovascular disease. Hypertension. 2018; 72(4): 986-993, doi: 10.1161/HYPERTENSIONAHA.118.11337, indexed in Pubmed: 30354704.

16. Lipsitz L, Habtemariam D, Gagnon M, et al. Reexamining the Effect of Antihypertensive Medications on Falls in Old Age. Hypertension. 2015; 66(1): 183-189, doi: 10.1161/hypertensionaha.115.05513.

17. Schneider S, Promny D, Sinnecker D, et al. Impact of sympathetic renal denervation: a randomized study in patients after renal transplantation (ISAR-denerve). Nephrol Dial Transplant. 2015; 30(11): 1928-1936, doi: 10.1093/ndt/gfv311, indexed in Pubmed: 26333545.

18. Vinik Al, Ziegler D. Diabetic cardiovascular autonomic neuropathy. Circulation. 2007; 115(3): 387-397, doi: 10.1161/CIRCULATIONAHA.106.634949, indexed in Pubmed: 17242296

19. Gerhardt U, Schäfer M, Hohage H. Arterial blood pressure oscillation after active standing up in kidney transplant recipients. J Auton Nerv Syst. 2000; 80(1-2): 93-100, doi: 10.1016/s0165-1838(00)00078-3, indexed in Pubmed: 10742546.

20. Shibao C, Grijalva CG, Lipsitz LA, et al. American Society of Hypertension Writing Group. ASH position paper: evaluation and treatment of orthostatic hypotension. J Clin Hypertens (Greenwich). 2013; 15(3): 147-153, doi: 10.1111/jch.12062, indexed in Pubmed: 23458585.

21. Julius S, Palatini P, Kjeldsen SE, et al. Usefulness of heart rate to predict cardiac events in treated patients with high-risk systemic hypertension. Am J Cardiol. 2012; 109(5): 685-692, doi: 10.1016/j. amjcard.2011.10.025, indexed in Pubmed: 22169130.

22. Khurana A, McCuskey CF, Slavcheva EG. Orthostatic hypotension in kidney pancreas transplant patients and its relation to preexisting autonomic neuropathy. Exp Clin Transplant. 2008; 6(2): 127-131, indexed in Pubmed: 18816239.

23. Ward C, Kenny RA. Reproducibility of orthostatic hypotension in symptomatic elderly. Am J Med. 1996: 100(4) : 418-422, doi: 10.1016/S00029343(97)89517-4, indexed in Pubmed: 8610728 